\title{
O DESFIBRILADOR EXTERNO AUTOMÁTICO NO SUPORTE BÁSICO DE VIDA
}

\author{
Marilaine M. de Menezes Ferreira ${ }^{\alpha}$ \\ Renata Luzia de Lima Costa ${ }^{b}$ \\ Rosemeire Oliveira Moreira Menezes ${ }^{c}$
}

\begin{abstract}
Resumo
O uso do DEA por pessoas leigas em episódios ocorridos no âmbito extra-hospitalar pode salvar vidas de acordo com o tempo entre a PCR e a desfibrilação. No Brasil a presença do DEA em ambientes de grande circulação de público é obrigatório por lei municipal ou distrital. Este estudo tem como objetivo verificar o conhecimento dos funcionários de uma instituição de ensino privada de Salvador onde há o DEA para uso, quanto ao seu uso e funcionamento, bem como apontando os locais públicos que tenham o DEA disponível. Trata-se de um estudo de campo, de natureza exploratória e abordagem quantitativa. Participaram dessa pesquisa 130 funcionários técnicos administrativos que responderam um questionário. Observou-se que $54,6 \%$ dos participantes sabem o que é o DEA. Destes, $54,6 \%$ afirmam não saber identificar os locais públicos onde é encontrado o DEA e os demais $45,4 \%$ que afirmam saber, responderam de forma correta $(76,9 \%)$. Identificou-se que apenas $43,8 \%$ dizem ter conhecimentos técnicos, porém $70,8 \%$ não fariam as manobras de primeiros socorros e apenas acionariam o Serviço de Emergência. 80\% afirmaram não conhecer o DEA e apenas 9,1\% responderam corretamente os passos para o uso do DEA. A partir dos dados obtidos, observou-se a necessidade de intervenção por parte da instituição, de propiciar treinamentos, a fim de capacitar e exercitar o conhecimento e agilidade dos seus colaboradores, contribuindo com condutas efetivas para diminuir as taxas de mortalidade por PCR, aumentando as chances de sobrevida das possíveis vítimas que possam ocorrer em ambiente público na presença destes profissionais.
\end{abstract}

Palavras-chave: Parada Cardíaca; Educação em Saúde; Desfibrilação Elétrica.

\footnotetext{
a. Enfermeira. Mestre em Família na Sociedade Contemporânea. Professora Assistente do curso de Enfermagem da Escola Bahiana de Medicina e Saúde Pública.marilaine.menezes@hotmail.com

b. Graduanda do curso de enfermagem da Escola Bahiana de Medicina e Saúde Pública. renata_luzia@hotmail.com

c. Graduanda do curso de enfermagem da Escola Bahiana de Medicina e Saúde Pública. rommenezesı@hotmail.com
} 


\title{
THE AUTOMATIC EXTERNAL DEFIBRILLATOR IN BASIC LIFE SUPPORT
}

\begin{abstract}
The use of AEDs by laypersons in episodes occurred outside hospitals can save lives according to the time between cardiac arrest and defibrillation. In Brazil, the presence of DEA in environments of great public transit is required by municipal or district law. This study aims to evaluate the knowledge of employees of a private education institution of Salvador in which there is an AED available for use, as to its function and operation, as well as pointing out public locations where AED is available. This is a field study of exploratory and quantitative approach. 130 administrative staff participated in this research through a questionnaire. It was observed that $54.6 \%$ of the participants know what an AED is. Of these, $54.6 \%$ said they did not know how to identify public places where an AED is found and the remaining $45.4 \%$ who claim to know, answered correctly $(76.9 \%)$. It was found that only $43.8 \%$ say they have technical expertise, but $70.8 \%$ would not make the first aid maneuvers and would only call the Emergency Service. $80 \%$ said they did not know an AED, and only $9.1 \%$ answered correctly the steps to use the AED. From the data obtained, it was observed the need for intervention by the institution to provide training in order to teach and exercise the knowledge and agility of its employees, contributing to effective conducts for reducing mortality rates by $P C R$, increasing the chances of survival of the possible victims that may occur in the presence of these professionals.
\end{abstract} Keywords: Cardiac Arrest; Health Education; Electrical Defibrillation.

\section{EL SOPORTE VITAL BÁSICO DESFIBRILADOR AUTOMÁTICO EXTERNO EN}

\section{Resumen}

El uso de AED por profanos episodios ocurrió en el entorno extrahospitalario puede salvar vidas de acuerdo con el tiempo que transcurre entre un paro cardíaco y desfibrilación. En Brasil, la presencia de la DEA en una gran circulación de ambientes públicos es requerida por la ley municipal o del condado. Este estudio tiene como objetivo determinar el conocimiento de los empleados de una universidad privada en Salvador, donde está la DEA a utilizar, en cuanto a su uso y funcionamiento, así como señalar los lugares públicos que tienen un DEA disponible. Se trata de un estudio de campo de enfoque exploratorio y cuantitativo. En este estudio participaron 130 empleados del personal administrativo que respondieron a un cuestionario. Se observó que el 54,6\% de los participantes saben lo que el DEA. De éstos, el 54,6\% dijo que no sabía cómo identificar lugares públicos donde se encuentra la DEA y el otro $45,4 \%$ que dicen saber, respondió correctamente $(76,9 \%)$. Se encontró que sólo el $43,8 \%$ dicen que no tienen conocimientos técnicos, pero el $70,8 \%$ no hacer las primeras maniobras de ayuda y sólo daría lugar a la sala de urgencias. $80 \%$ dijo que no sabía que la DEA, y sólo el 9,1\% respondió correctamente los pasos para utilizar el DEA. De los datos obtenidos, se observó la necesidad de la intervención de la institución para brindar capacitación con el fin de entrenar y ejercitar los conocimientos y la agilidad de sus empleados, lo que contribuye a los comportamientos eficaces para reducir las tasas de mortalidad por PCR, aumentando las posibilidades de supervivencia de las posibles víctimas que se puedan producir en el ámbito público, en presencia de estos profesionales.

Palabras clave: Paro cardíaco; Educación para la Salud La desfibrilación eléctrica. 


\section{INTRODUÇÃO}

A Parada Cardiorrespiratória (PCR) é a cessação abrupta da função mecânica cardíaca, ocorrendo, consequentemente, a parada dos outros órgãos vitais devido à falta de oxigenação, e, por conseguinte, da respiração. (1) Segundo dados da OMS, foram 17,5 milhões de óbitos por doenças cardiovasculares (30\%) em 2005, e mais da metade ocorreram de forma súbita. Essas mortes súbitas, devido a ataques cardíacos, possuem altas taxas também nos EUA que, estima-se anualmente, por volta de 250 mil mortes de pessoas que não ocorrem em hospitais. (2) A cardiopatia isquêmica se sobressai entre as doenças, sendo considerada como causa significativa de mortes atuais. ${ }^{(2-8)}$

Foi observado que, em $85 \%$ dos casos de atendimento extra-hospitalar, que resultaram em morte súbita, a Fibrilação Ventricular (FV) e a Taquicardia Ventricular (TV) sem pulso foram os ritmos cardíacos detectados. Nesses casos, o único tratamento recomendado é a desfibrilação e a implementação rápida e eficaz das técnicas de Reanimação Cardiopulmonar. Porém, devido à demora do socorro, muitos casos de FV inicial podem degenerar para a assistolia. Nota-se então que é de extrema importância a agilidade no atendimento à vítima de $P C R$, podendo dobrar ou triplicar a sobrevida do indivíduo já que a taxa de sobrevivência por FV diminui de 7 a $10 \%$ por minuto de demora em realizar a primeira desfibrilação. Dessa forma, a desfibrilação cardíaca é a maneira mais efetiva para aumentar a expectativa de sobrevivência. ${ }^{(2-4,6,6,9,10)}$

A primeira técnica de desfibrilação com êxito ocorreu em 1933, em animais. Em 1947, foi aplicada uma corrente elétrica diretamente no coração humano, usando corrente alternada. Surgiu então, posteriormente, através do Dr. Leonard Cobb, o conceito da utilização do método de desfibrilação em ambientes públicos. Esse conceito foi então divulgado pela American Heart Association (AHA). O mesmo relatava que, para os episódios que ocorressem no âmbito extra-hospitalar, o uso do Desfibrilador Externo Automático (DEA) por pessoas leigas poderiam salvar vidas de acordo com o tempo entre a PCR e a desfibrilação. Desde então, a experiência com programas de desfibrilação de emergência realizada por paramédicos tem demonstrado repetidamente que a desfibrilação precoce pode salvar vidas e melhorar a chance de sobrevivência. ${ }^{(11-13)}$

O DEA é um equipamento portátil, que possui um sistema computadorizado. Esse sistema analisa o ritmo cardíaco várias vezes em poucos segundos, através de eletrodos fixados ao paciente, detectando a necessidade da desfibrilação, que é um choque elétrico controlado a partir da presença de uma arritmia cardíaca geradora da PCR (FV e TV sem pulso), que é tida como ritmo cardíaco desfibrilável. Essa identificação permite o aparelho carregar e recomendar a aplicação do choque por meio de uma mensagem. ${ }^{(6,14,15)}$

A desfibrilação era um procedimento reservado à profissionais de saúde treinados em Suporte Avançado de Vida. Como os DEAs, atualmente, apresentam versões de simples manuseio, pode ser realizado por leigos ou profissionais que possuam treinamento no Suporte Básico de Vida (SBV). ${ }^{(15)}$

Em um estudo realizado em Rochester, Minnesota, através de uma longa observação e testes realizados em atendimentos por policiais que foram treinados para o uso do DEA, ocorreu uma melhora de desempenho e sobrevivência. Esse fato também foi observado em estudos realizados com o uso do DEA em aeronaves comerciais em Seattle e em aeroportos em Chicago. Já em ambiente extra -hospitalar com grande fluxo de pessoas, realizado em Vancouver, no período da pesquisa ocorreram 5 casos de PCR e em 2 o ritmo era desfibrilável e obteve-se sucesso, estando os pacientes recobrando a consciência quando o serviço de emergência chegou ao local. Já na Escócia, foi considerado que a utilização do DEA em locais públicos, adequados, aumentaria a sobrevivência de 744 casos (5\%) a 942 casos $(6,3 \%) \cdot(3,5,13,16)$ 
Devido à urgência pela reversão do quadro e consequentemente, um socorro rápido, as novas diretrizes da AHA e o International Liaison Committee on Resuscitation (ILCOR) consideram a desfibrilação como um procedimento de Suporte Básico de Vida. Para uma melhor organização e desempenho, foi criada a "Corrente de Sobrevida" que inclui o reconhecimento da PCR e acionamento do serviço de emergência/urgência, a RCP precoce com ênfase nas compressões torácicas, a desfibrilação imediata, o atendimento para o Suporte Avançado e os cuidados pós-PCR, com instruções para profissionais de saúde e leigos, já que, esses últimos são os que mais comumente presenciam a cena. ${ }^{(12,17,18)}$

Em comunidades, o tempo médio de socorro pelo serviço especializado é de 7- 8 minutos, ou mais, revelando a importância dos socorristas leigos nesses momentos. ${ }^{(2)}$ Este é um ponto importante a ser abordado, pois é fundamental o aprendizado para a utilização do DEA por leigos, já que o mesmo encontra-se a disposição em locais públicos. ${ }^{(11,12)}$

Em algumas cidades e estados brasileiros a presença do DEA em ambientes de grande circulação de público é obrigatório por lei municipal ou distrital, como São Paulo, Maranhão, Salvador e outros. Além disso, em instituições de ensino com concentração ou circulação média diária a partir de mil e quinhentas pessoas, fica obrigada a possuir aparelho desfibrilador externo automático. ${ }^{(2,3,12,19,20)}$ A realização deste trabalho acerca do tema remete à experiência e interesse das autoras, conquistado através da participação na Liga Acadêmica de Primeiros Socorros (LAPS), permitindo uma análise crítica da precariedade de estudos e, contraditoriamente, a importância e a diferença que um socorro imediato e correto, utilizando o DEA, decisivos no contexto vida - morte em vítimas de PCR. Relatos vivenciados por pessoas, que tiveram a oportunidade de realizar os procedimentos conjugados, no final do ano de 2012, confirmam a importância deste estudo, servindo como reforço de interesse na pesquisa.
Esse trabalho teve como objetivo, verificar o conhecimento dos funcionários técnicos e administrativos de uma instituição ensino privada a respeito do Desfibrilador Externo Automático (DEA) e sobre os locais públicos que possuam o equipamento.

\section{METODOLOGIA}

Foi realizado um estudo de campo, do tipo exploratório, de natureza descritiva, desenvolvido em uma Instituição de Ensino Superior privada de Salvador, Bahia. Este espaço foi escolhido por ser uma instituição de ensino de referência na área da saúde com fácil acesso para a realização da pesquisa.

A população de estudo foi composta pelos profissionais do setor técnico e administrativo que atuam em um dos campus da instituição, e que consentiram fazer parte da pesquisa. Os critérios de exclusão dos participantes foram: aqueles que não são alfabetizados, por não ser possível ler e responder o questionário; pessoas com idade inferior a 18 anos, pois não apresentam maioridade e pessoas que apresentem dificuldades de interpretar logicamente as questões.

Esses profissionais foram escolhidos por ser uma população que trabalha em uma instituição de saúde, mas em cargos que não são voltados para a atenção em saúde, visto que é imprescindível o reconhecimento e uso da população a cerca do DEA para a redução do tempo da assistência prestada, com a preservação do prognóstico clínico da vítima, até a chegada do Sistema Médico de Urgência, evitando vítimas por morte súbita em ambientes extra-hospitalares.

De acordo com a lista fornecida pela Administração da instituição, o quantitativo de profissionais a serem incluídos para participar da pesquisa foi de 150 (cento e cinquenta) funcionários trabalhando nesse campus.

Deste total, 14 funcionários se recusaram a participar, o3 estavam de férias durante o período de coleta, 02 de licença maternidade durante o período 
de coleta e o1 não era alfabetizado. Participaram, então, 130 (cento e trinta) funcionários. A presente pesquisa foi submetida à análise do Comitê de Ética em Pesquisa da Escola Bahiana de Medicina e Saúde Pública e encontra-se em conformidade com os princípios da Resolução 466/12, do Conselho Nacional de Saúde, que se refere aos aspectos sobre pesquisa envolvendo seres humanos; tendo sido aprovado sob o número do Parecer 399.280/13.

A coleta de dados foi efetuada pelas autoras, após autorização do Comitê de Ética em Pesquisa e da instituição de ensino, no período de 20 de setembro a 05 de outubro de 2013 em 5 períodos, nos quais foram 3 dias pela manhã e 2 pela tarde, no período de trabalho de cada funcionário. Foram utilizados os procedimentos para a realização da pesquisa: abordagem direta aos participantes, que aconteceu no local de trabalho de cada um deles; explicação dos objetivos da pesquisa e solicitação de concordância em participar da pesquisa, sendo necessária a assinatura do Termo de Consentimento Livre e Esclarecido (TCLE); entrega do questionário desenvolvido pelas autoras contendo 11 (onze) questões fechadas, sendo da $1^{\mathrm{a}}$ a $4^{\mathrm{a}}$ questão são referentes à identificação do participante da pesquisa, e da $5^{\mathrm{a}}$ a $11^{\mathrm{a}}$, que proporcionam revelar o conhecimento acerca do tema, que se referiram a conceito do que é o DEA, por qual meio de comunicação foi informado sobre o DEA, em que locais públicos esse equipamento é encontrado, como chamaria ajuda, se possui treinamento para isso e sabe utilizá-lo.

A participação dos funcionários foi voluntária e sigilosa. Os questionários foram respondidos na presença das autoras e recolhidos logo após o tér- mino do preenchimento sendo dado tempo livre. O tempo médio para a devolução dos questionários respondidos foi de 03 (três) minutos. Todos os questionários foram respondidos completamente.

Os resultados da pesquisa foram obtidos por meio da análise das respostas dos participantes. Das variáveis referentes à faixa etária, gênero, escolaridade e conhecimentos técnicos sobre o tema foi feita uma análise descritiva por percentual das respostas de cada item e os valores encontrados foram apresentados em tabelas e gráficos.

O mesmo foi feito com as questões referentes à localização do aparelho, função e conhecimento acerca do tema. Porém, o percentual dividiu-se em respostas certas e erradas.

As tabelas foram apresentadas de modo que permitiu ser possível visualizar o retorno obtido e os dados foram contabilizados três vezes para evitar erros tabulados. Os dados foram processados no programa Microsoft Office Excel 2007 e foram calculadas as porcentagens através de regra de três simples.

Os dados encontrados foram confrontados com referências bibliográficas de diferentes autores para a discussão deste estudo.

\section{RESULTADOS E DISCUSSÕES}

Participaram dessa pesquisa 130 funcionários técnicos e administrativos de uma instituição privada de Salvador. Os Gráficos de 1 a 4 apresentam a caracterização dos participantes da pesquisa, em relação à faixa etária, escolaridade, gênero e se possui algum conhecimento técnico na área de saúde. 
Gráfico 1 - Faixa etária dos funcionários

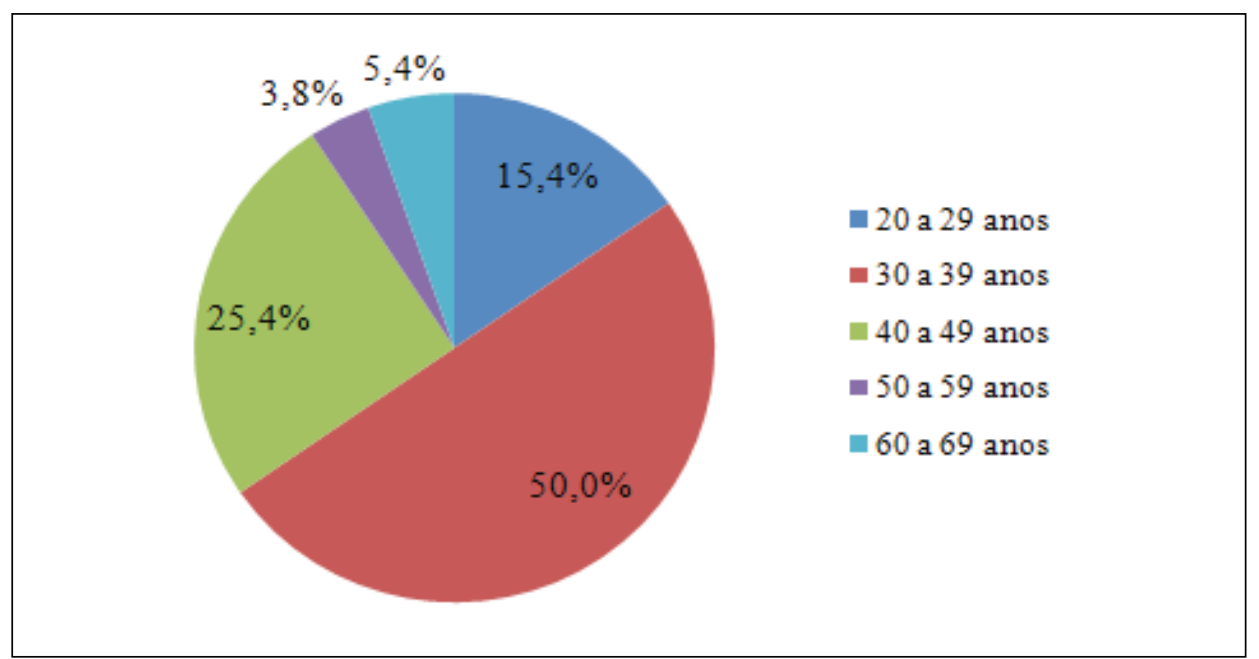

Fonte: Elaborado pelas autoras. 2013.

Gráfico 2 - Escolaridade dos funcionários

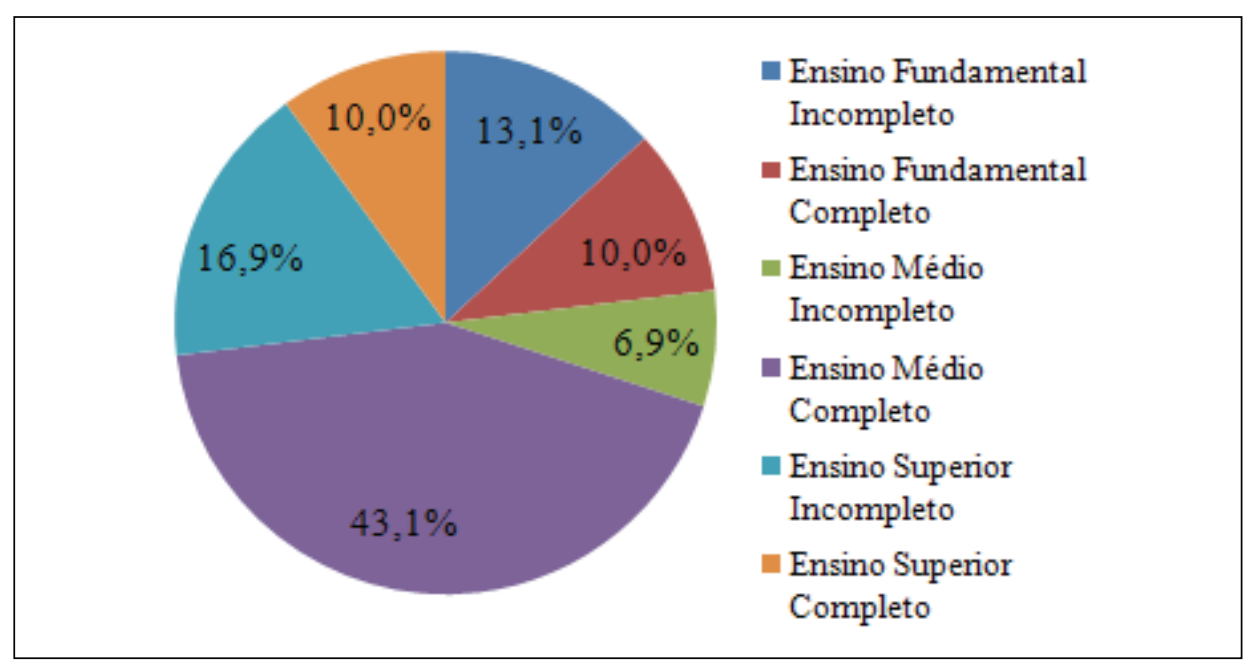

Fonte: Elaborado pelas autoras. 2013.

Gráfico 3 - Gênero dos funcionários

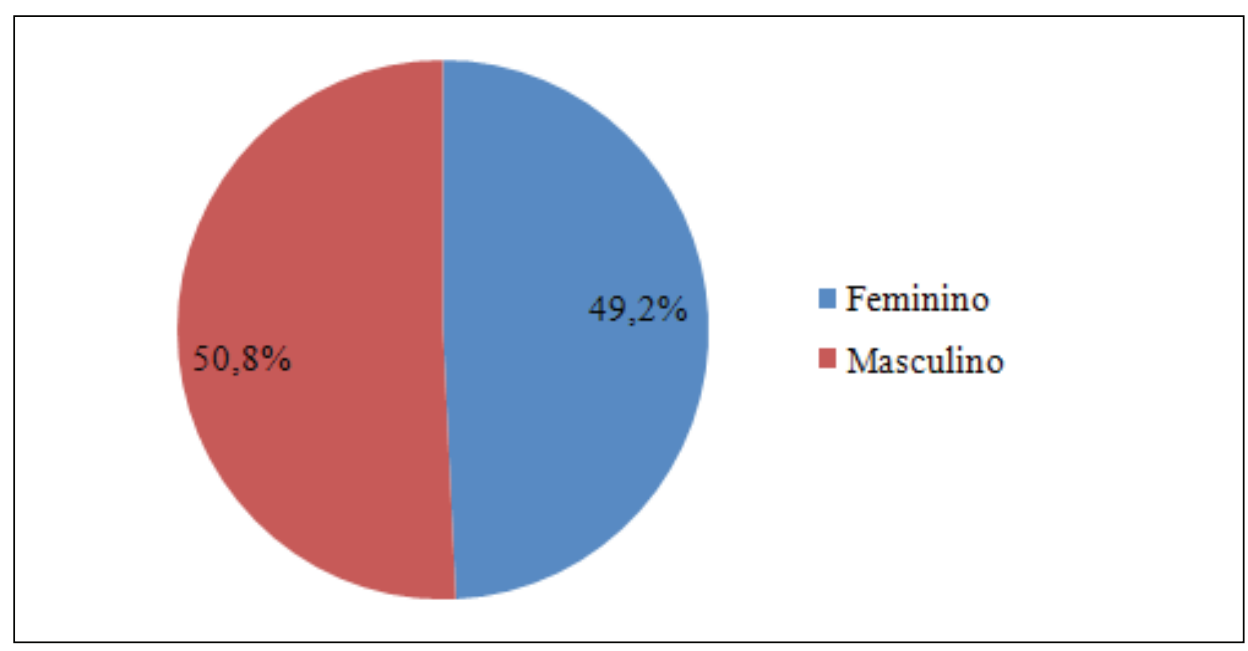

Fonte: Elaborado pelas autoras. 2013. 
Gráfico 4 - Conhecimento técnico dos funcionários na área de saúde

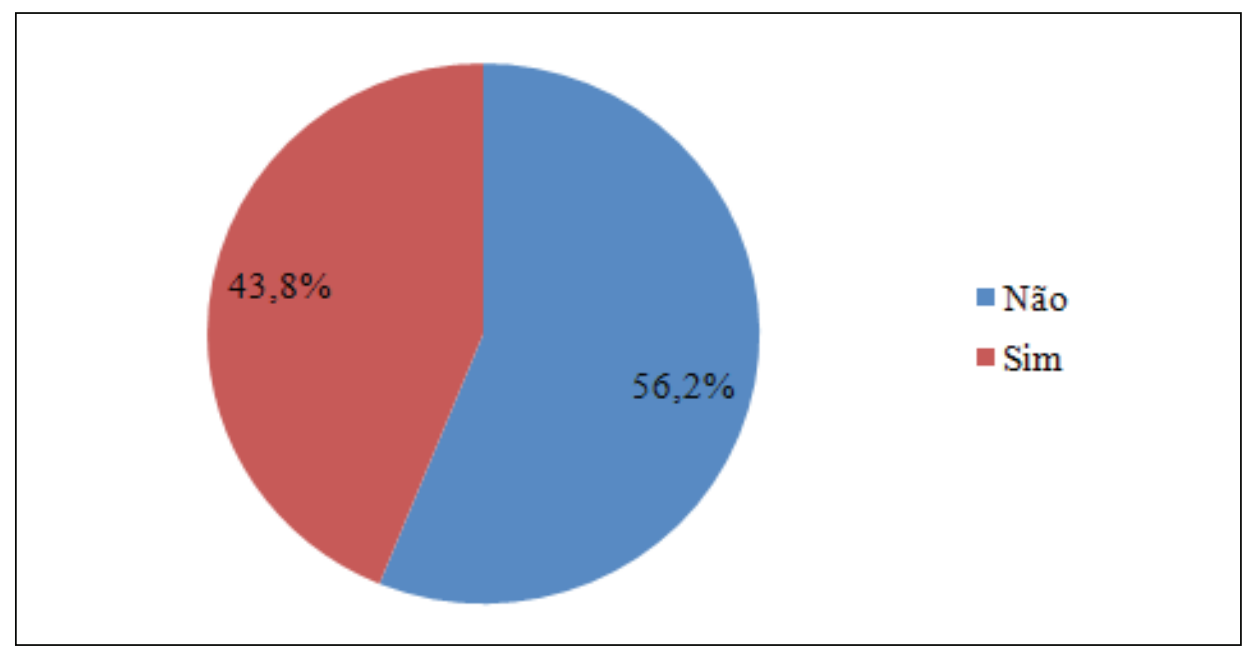

Fonte: Elaborado pelas autoras. 2013.

No Gráfico 1 é possível observar que a maioria dos participantes pertence à faixa etária dos 30 a 39 anos, seguidos da faixa de 40 a 49 anos, representando, respectivamente, $50 \%$ e $25,4 \%$. No Gráfico 2 , em relação à escolaridade, a predominância é de participantes com ensino médio completo $(43,1 \%)$, seguido pelo ensino superior incompleto $(16,9 \%)$. Já em relação ao gênero, 50,8\% são do gê- nero masculino, enquanto $49,2 \%$ são do gênero feminino. Quando se trata do conhecimento técnico na área de saúde, 43,8\% dizem possuir. Ao determinar seus conhecimentos técnicos na área de saúde, os participantes consideraram que algumas vezes já participaram de algum curso de primeiros socorros e/ou aqueles que têm formação técnica em enfermagem.

Tabela 1 - Relação entre escolaridade e conhecimento técnico na área de saúde

\begin{tabular}{l|c|c}
\hline \multirow{2}{*}{\multicolumn{1}{c|}{ EsCOLARIDADE }} & \multicolumn{2}{c}{ CONHECIMENTO TÉCNICO } \\
\cline { 2 - 3 } & $\mathrm{N}$ & $\%$ \\
\hline Ensino Fundamental Incompleto & 8 & $14,0 \%$ \\
\hline Ensino Fundamental Completo & 5 & $8,8 \%$ \\
\hline Ensino Médio Incompleto & 6 & $10,5 \%$ \\
\hline Ensino Médio Completo & 28 & $49,1 \%$ \\
\hline Ensino Superior Incompleto & 9 & $15,8 \%$ \\
\hline Ensino Superior Completo & 1 & $1,8 \%$ \\
\hline Total geral & $\mathbf{5 7}$ & $\mathbf{1 0 0 \%}$ \\
\hline
\end{tabular}

Fonte: Elaborado pelas autoras, 2013

Na Tabela 1 nota-se que o conhecimento técnico na área de saúde apresenta valores mais significantes em pessoas que o nível de escolaridade é menor. Pode-se inferir que, por esses profissionais de ensino superior completo e incompleto trabaIhem em locais específicos e/ou isolados, não possuindo contato constante com os alunos, tenham um distanciamento da necessidade de um apren- 
dizado de primeiros socorros. Essa inferência parte da verificação que $14,0 \%$ dos funcionários com conhecimento técnico têm ensino fundamental incompleto e apenas 1,8\% no ensino superior completo o detém.

Gráfico 5 - Conhecimento o que é DEA

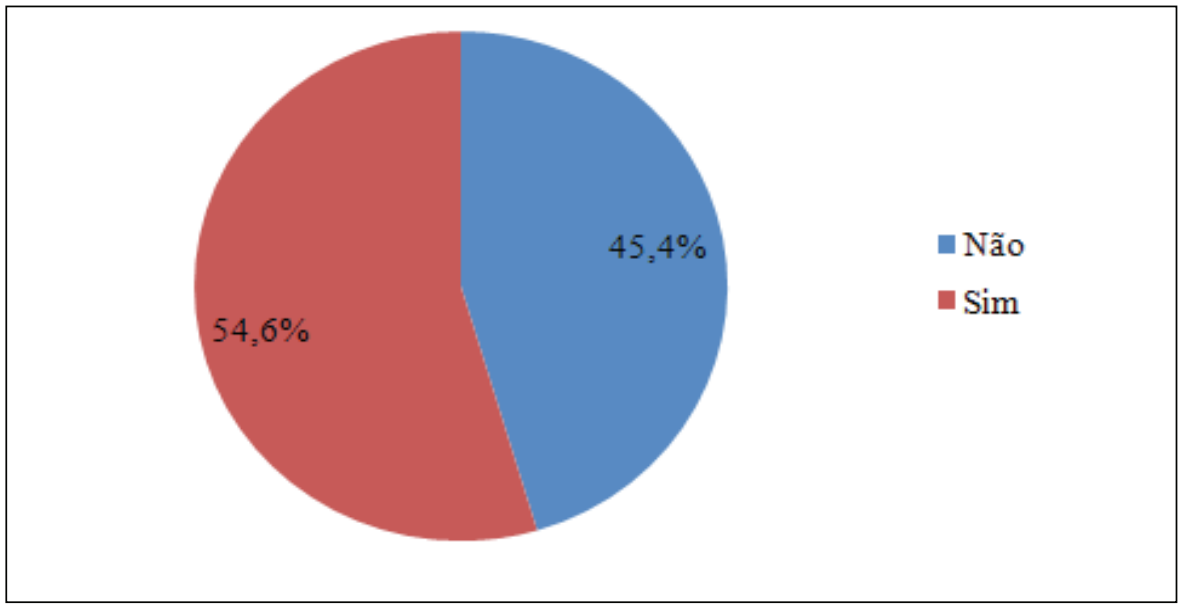

Fonte: Elaborado pelas autoras, 2013.

Tabela 2 - Meios de comunicação que foram fonte de informação para conhecimento do DEA

\begin{tabular}{|c|c|c|}
\hline MEIOS DE COMUNICAÇÃO & $\mathrm{N}$ & $\%$ \\
\hline Jornal & 24 & $16,7 \%$ \\
\hline Futebol & 29 & $20,1 \%$ \\
\hline Televisão & 32 & $22,2 \%$ \\
\hline Revistas & 8 & $5,6 \%$ \\
\hline Internet & 12 & $8,3 \%$ \\
\hline Livros & 9 & $6,3 \%$ \\
\hline Aula sobre o tema & 30 & $20,8 \%$ \\
\hline Total Geral & 144 & $100 \%$ \\
\hline
\end{tabular}

Fonte: Elaborado pelas autoras, 2013.

Como demonstrado no Gráfico 5, mais da metade $(54,6 \%)$ dos participantes sabem o que é o Desfibrilador Externo Automático (DEA), enquanto que os outros $45,4 \%$ responderam que não sabiam o que era. Conforme a Tabela 2, os funcionários informaram que ficaram cientes da existência do DEA através de meios como televisão (através de filmes e novelas), jornal e futebol. Foi possível observar, através dos dados coletados, que os participantes do gênero masculino que sabem o que é DEA obtiveram a informação da sua existência, através, principalmente, do futebol. Frequentemente tem sido evidenciado pela mídia esportiva sobre eventos onde ocorrem situações com óbitos por PCR tanto de jogadores e espectadores que se encontravam nos estádios. ${ }^{(21)}$ 
Gráfico 6 - Conhecimento dos locais públicos com DEA

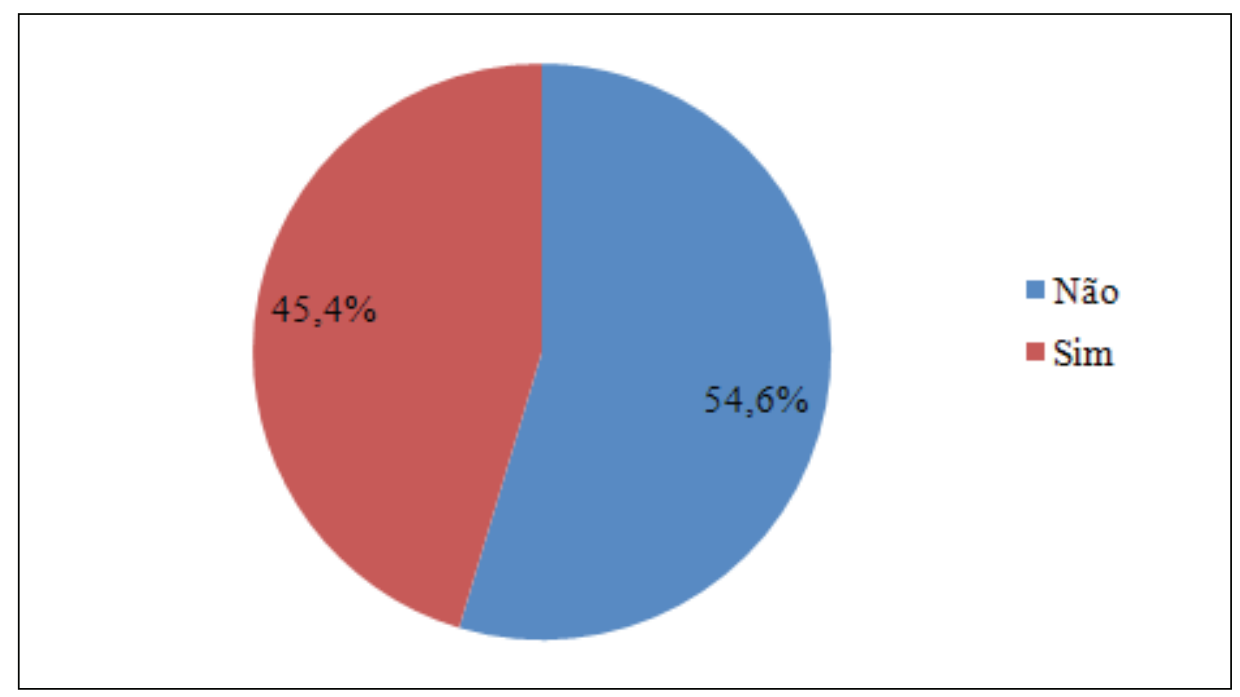

Fonte: Elaborado pelas autoras, 2013.

Tabela 3 - Locais públicos que possuem DEA

\begin{tabular}{l|c|c}
\hline \multicolumn{1}{c|}{ Locals } & N & $\%$ \\
\hline Praia & O4 & $2,7 \%$ \\
\hline Shopping & 36 & $24,3 \%$ \\
\hline Aeroporto & 50 & $33,8 \%$ \\
\hline Rodoviária & 32 & $21,6 \%$ \\
\hline Rua & $\mathrm{O} 2$ & $1,4 \%$ \\
\hline Estação de ônibus & 24 & $16,2 \%$ \\
\hline Total Geral & $\mathbf{1 4 8}$ & $\mathbf{1 0 0 \%}$ \\
\hline
\end{tabular}

Fonte: Elaborado pelas autoras, 2013.

Embora um grande número de participantes saiba o que é o DEA, ao serem questionados sobre em quais locais públicos esse aparelho pode ser encontrado, 54,6\% afirmaram não saber, como mostrado no Gráfico 6. Dos 45,4\% que afirmaram saber os locais, aeroporto, shopping e rodoviária foram os mais citados, com 33,8\%, $24,3 \%$ e $21,6 \%$ respectivamente. Dessa forma, evidencia-se que, embora a maioria dos participantes tenha afirmado não saber, os que responderam afirmativamente responderam de forma correta os locais públicos que possuem o DEA, representando um total de $76,9 \%$ de respostas corretas.

Locais como rua e praia, que não possuem o aparelho e que foram adicionados ao questionário para saber se eles realmente haviam conhecimento foram assinalados em 2 e 4 questionários, respectivamente, como pode ser visto na Tabela 3.

De acordo com a Lei no 19.212/2011 do Deputado Estadual José de Arimatéia, é decretado que "aeroportos, shopping centers, centros empresariais, estádios de futebol, hotéis, hipermercados e supermercados, casas de espetáculos e locais de trabalho com concentração acima de 1.000 (mil) pessoas ou circulação média diária de 3.000 (três mil) ou mais pessoas, os clubes e academias com mais de 1.000 (mil) sócios, as instituições financeiras e de ensino com concentração ou circulação média diária de 1.500 (mil e quinhentas) ou mais pessoas, ficam obrigados a manter, em suas dependências, aparelho desfibrilador externo automático." Além disso, os equipamentos devem estar presentes nos estabelecimentos em 
quantidade suficiente e os profissionais que trabaIham nesses locais acima citados deverão possuir capacitação promovida por meio de curso ministrado de acordo com as recomendações do Conselho Nacional de Ressuscitação. ${ }^{(20)}$

Tabela 4 - Modo de acionar ajuda

\begin{tabular}{l|c|c}
\hline \multicolumn{1}{c|}{ AJUDA } & N & $\%$ \\
\hline Chamaria o Serviço de Emergência & 88 & $57,9 \%$ \\
\hline Chamaria Alguém Próximo & 23 & $15,1 \%$ \\
\hline Forneceria os Primeiros Socorros até a chegada do socorro & 34 & $22,4 \%$ \\
\hline Não saberia como fazer & 07 & $4,6 \%$ \\
\hline Total Geral & $\mathbf{1 5 2}$ & $\mathbf{1 0 0 \%}$ \\
\hline
\end{tabular}

Fonte: Elaborado pelas autoras, 2013.

$\mathrm{Na}$ Tabela 4, ao serem questionados como eles acionariam ajuda, em $57,9 \%$ responderam que chamariam o serviço de emergência (SAMU), o que proporciona socorro especializado sem riscos de atendimento errado à vítima.

Gráfico 7 - Relação conhecimento técnico e realização de primeiros socorros

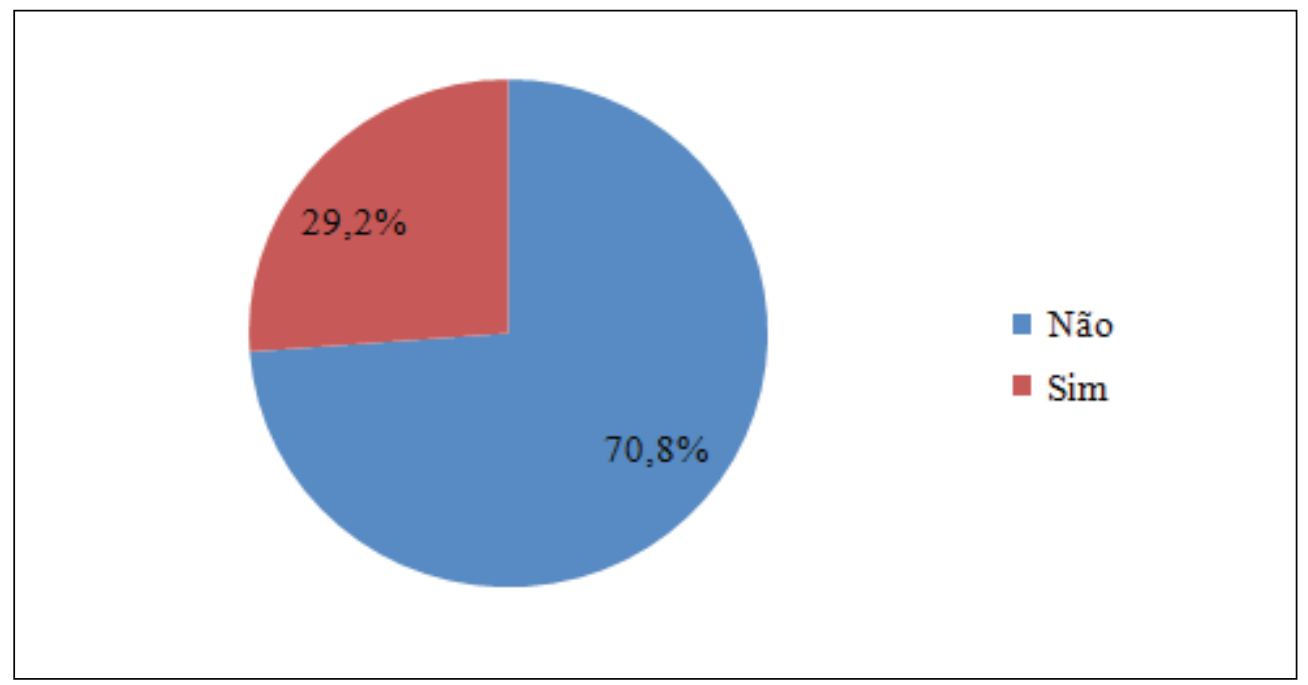

Fonte: Elaborado pelas autoras, 2013.

Porém, existem também aqueles que têm conhecimento técnico e não realizariam os primeiros socorros, que totalizam $29,2 \%$ dos entrevistados. Pode se inferir que esses indivíduos não se sentem seguros em realizar os primeiros socorros. Esses casos, de acordo com a Lei $2848 / 40$ - Art. 135 do
Código Penal, não são considerados como omissão de socorro, já que o prestador de socorro ligou para o serviço de emergência. ${ }^{(22)}$ Entretanto, somente o pedido de ajuda especializada não é benéfico para a vítima já que a associação de compressões torácicas eficazes melhora a chance de sobrevivência. ${ }^{(17)}$ 


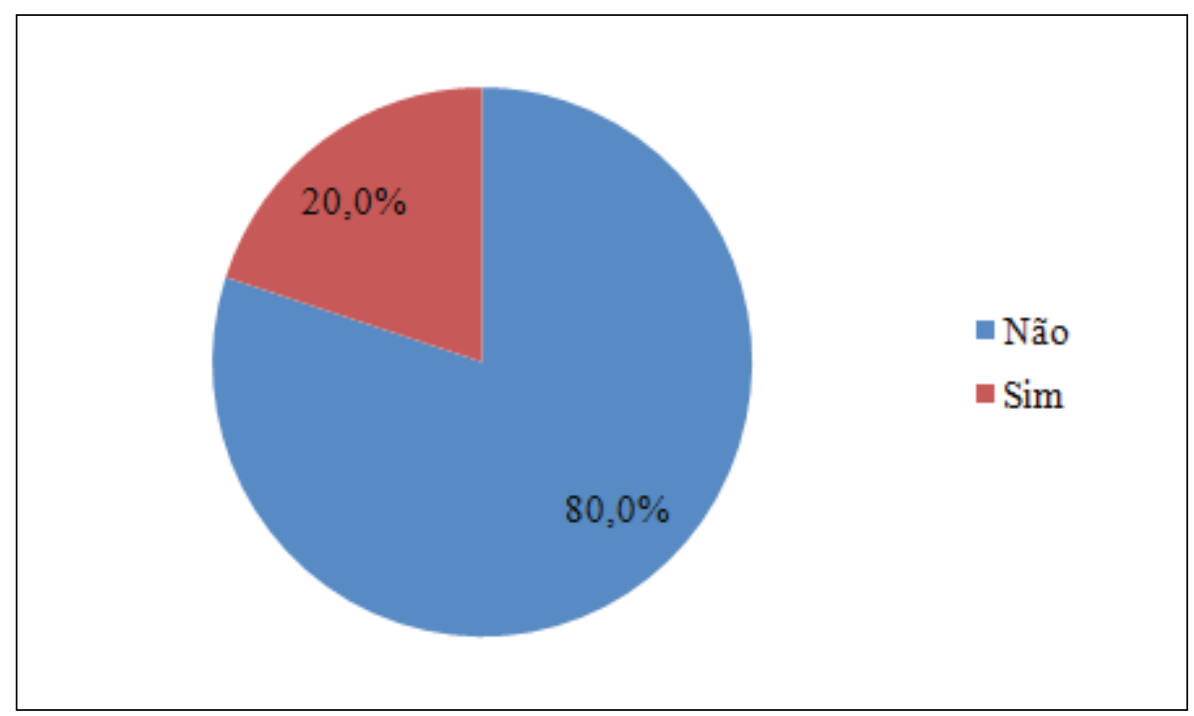

Fonte: Elaborado pelas autoras, 2013.

Como é visto no Gráfico 8, em relação aos participantes que já tiveram contato e/ou treinamento com o DEA, $104(80 \%)$ responderam negativamente, enquanto que apenas 26 (20\%) afirmaram ter tido contato e/ou treinamento. Os participantes que fazem parte de setores específicos que têm por objetivo compra, controle, manutenção e armazenamento desse aparelho já tiveram contato com o mesmo, e alguns já tiveram treinamento. Daqueles que responderam que já tiveram contato e/ou treinamento, $8 \%$ já presenciaram socorro e $10 \%$ realizaram treinamento. Alguns dos participantes, ao final da pesquisa, relataram que participaram do curso de treinamento oferecido pela Liga Acadêmica de Primeiros Socorros (LAPS) no ano de 2012.

Em situações de atendimento de emergência no ambiente extra-hospitalar, em específico a PCR e desfibrilação, cabe aos profissionais de enfermagem treinados a realização dos procedimentos, assim como outros indivíduos e profissionais com o treinamento de Suporte Básico de Vida, em conjunto com outros profissionais da saúde, conforme determinado em Decisão do COREN-SP n. 01/2001. ${ }^{(15,23)}$ Dessa forma, dos 57 profissionais (44\%) que possuem conhecimento técnico, apenas
21 (16\%) dizem possuir o treinamento necessário de acordo com a Lei, para seu uso em situações de emergência.

Estudos realizados nos aeroportos de Chicago exibiram vídeos curtos nas salas de espera, mostrados a cada 30 minutos, alertando sobre a disponibilidade do DEA, seu propósito e incentivando seu uso. Materiais impressos também foram disponibilizados ao público, além de 3 sessões de treinamentos públicos realizados em diferentes pontos de Chicago, com o apoio da mídia local e nacional promovendo o programa. Foi possível comprovar que, mesmo os indivíduos que não possuíram treinamento e não sabiam utilizar o aparelho foram encorajados, já que isso não é visto como uma desculpa de não utilizá-lo. Isso foi confirmado através de 6 pessoas que nunca haviam operado um DEA, nem foram treinados e as vítimas em PCR foram reanimados com sucesso e recobraram a consciência no ambiente. Dessa forma, é possível constatar que os leigos, mesmo sem conhecimento, são capazes de utilizar o desfibrilador e, consequentemente, salvar vidas, já que o mesmo é um aparelho autoexplicativo. ${ }^{(16)}$ 
Gráfico 9 - Uso do DEA por leigos

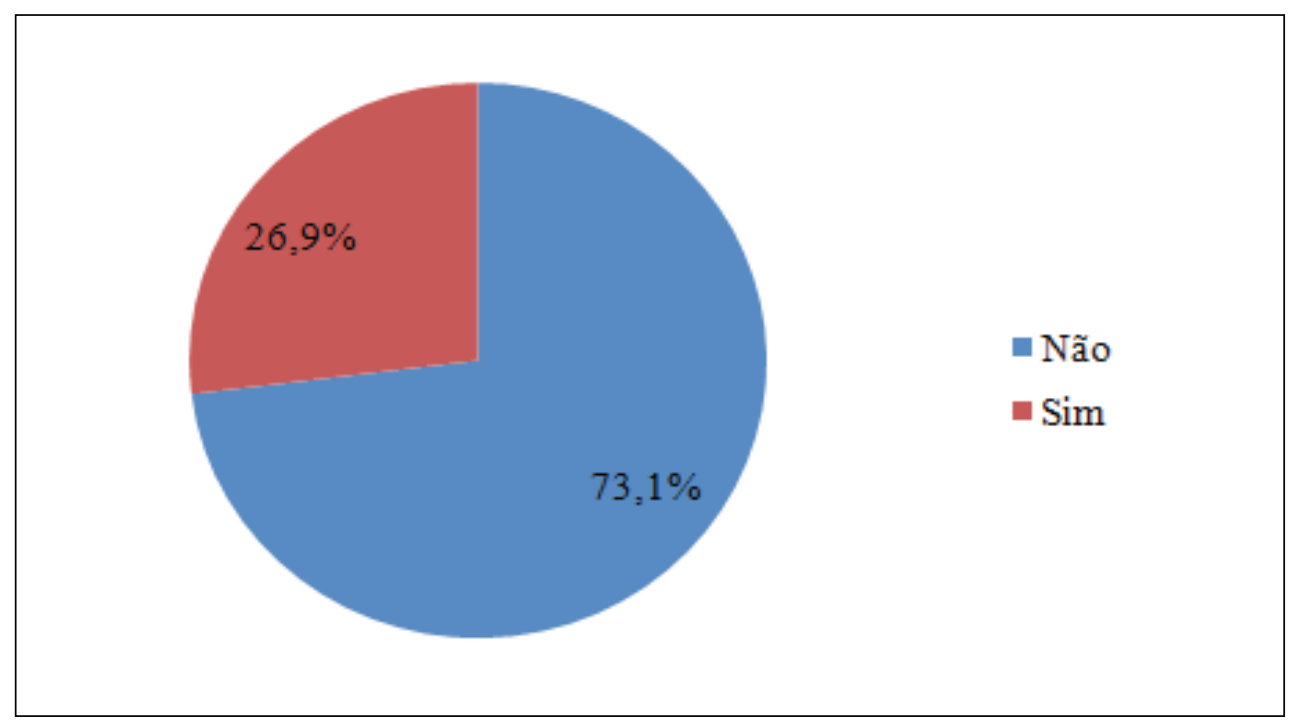

Fonte: Elaborado pelas autoras, 2013.

Ao serem questionados se o DEA pode ser usado por leigos, 95 participantes $(73,1 \%)$ disseram que não. Contraditoriamente, ao serem questionados se utilizariam o desfibrilador em uma situação de emergência, $49 \%$ responderam afirmativamente.

Operar o Desfibrilador Externo Automático consiste em seguir as instruções que são dadas pelo aparelho ao decorrer do tempo. O mesmo após ser ligado, inicia as mensagens de instrução, ensinando primeiramente a colocar os eletrodos de forma correta. Logo após ele identifica o ritmo cardíaco da pessoa. Se o mesmo for um ritmo desfibrilável (FV ou TV), ele irá solicitar que o socorrista se afaste para realização do choque. Caso não seja um ritmo desfibrilável, o desfibrilador irá ordenar a continuação das compressões torácicas. ${ }^{(6)}$

\section{Gráfico 10 - Operação do DEA}

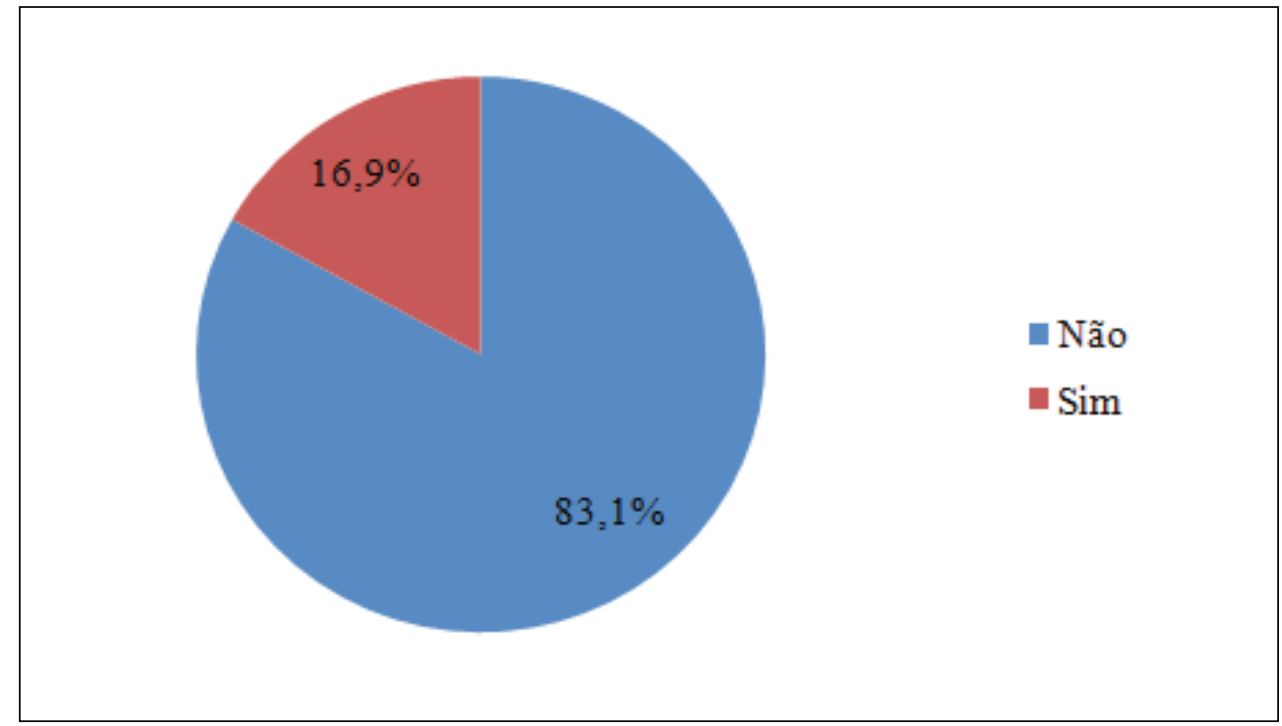

Fonte: Elaborado pelas autoras. 2013. 
Tabela 5 - Uso do DEA

\begin{tabular}{l|c|c}
\hline \multicolumn{1}{c|}{ COMO OPERAR O APARELHO } & N & $\%$ \\
\hline Colocar os eletrodos de forma correta & 10 & $22,7 \%$ \\
\hline Ligar o DEA & 08 & $18,2 \%$ \\
\hline Apertar os botões para dar o choque & 04 & $9,1 \%$ \\
\hline Esperar o aparelho, através de mensagens, sinalizar o que fazer & 22 & $50,0 \%$ \\
\hline Total Geral & $\mathbf{4 4}$ & $\mathbf{1 0 0 \%}$ \\
\hline
\end{tabular}

Fonte: Elaborado pelas autoras, 2013.

Os participantes que responderam saber operar o aparelho foram 44 (16,9\%), mas apenas $4(9,1 \%)$ marcaram nas assertivas todos os passos acima. Isso se deve ao fato do aparelho ser autoexplicativo, e os funcionários levarem em consideração a espera pelas mensagens de instrução, esquecendo-se dos outros passos que também são essenciais, como mostrado na Tabela 5.

\section{CONCLUSÃO}

Foi possível verificar com este estudo que mais da metade dos participantes sabem o que é o Desfibrilador Externo Automático (DEA), um conhecimento adquirido em maior parte através da mídia televisiva, embora a maioria $(54,6 \%)$ não consiga identificar os locais públicos a ser encontrado, comprometendo a agilidade no socorro. Os participantes que dizem saber $(45,4 \%)$ identificaram de forma correta $(76,9 \%)$ os locais públicos em que se encontra DEA.

Observou-se também, que não há relação entre nível de conhecimento com o de escolaridade, já que os participantes que informaram ter apenas nível médio demonstraram maior conhecimento sobre o assunto, considerando o fato de que a predominância dos cargos de nível superior pertencer às áreas administrativas.

Dos participantes que afirmam ter conhecimentos técnicos na área de saúde e contato/treinamento com o DEA (43,8\%), muitos se sentem inseguros para a prestação do socorro $(70,8 \%)$ e somente acionariam o Serviço de Atendimento Móvel de Urgência (SAMU). Identificou-se que, destes, 80\% não conhecem o equipamento e apenas $9,1 \%$ respondeu corretamente os passos para uso do DEA.

A partir desses dados, observou-se o interesse por parte dos participantes sobre o conhecimento e aprimoramento acerca do DEA, bem como a necessidade de intervenção por parte da instituição de propiciar constantes treinamentos, a fim de capacitar e exercitar o conhecimento e agilidade dos funcionários, permitindo e contribuindo com condutas efetivas, para diminuir as taxas de mortalidade por Parada Cardiorrespiratória, aumentando potencialmente as chances sobrevida das possíveis vítimas que possam ocorrer em ambiente público na presença destes profissionais.

\section{REFERÊNCIAS}

1. Semensato G, Zimerman L, Rohde LE. Avaliação inicial do Serviço de Atendimento Móvel de Urgência na Cidade de Porto Alegre. Arq. bras. cardiol. 2011; 96(3).

2. Gonzalez MM et al. Fibrilação ventricular durante atividade esportiva tratada com sucesso. Arq. bras. cardiol. 2009; 96(2).

3. Boa Ventura, AP. Avaliação do processo ensino aprendizagem das manobras de ressuscitação cardiorrespiratória $(R P C)$ utilizando o desfibrilador externo automático (DEA): alunos de graduação da área de saúde [tese]. São Paulo: Escola de Enfermagem da Universidade de São Paulo; 2010. 
4. Buss GAM et al. Alertas como fonte de conhecimento e base para ações regulatórias de tecnovigilância. Estudo de caso: desfibrilador externo automático. BIT - Boletim Informativo de Tecnovigilância. Brasília, 2011; 1.

5. Clementino JO. Condutas de enfermagem frente à parada cardiorrespiratória no contexto pré-hospitalar. [on line]. 2011. Disponível em: http://www.webartigos.com/ artigos/condutas-de-enfermagem-frente-aparada-cardiorrespiratoria-no-contexto-prehospitalar/65348/

6. Costa MPF, Mayadahira AMK. Desfibriladores externos automáticos (DEA) no atendimento pré-hospitalar e acesso público à desfibrilação: uma necessidade real. O Mundo Da Saúde. 2008;32(1):8-15.

7. Lister $\mathrm{P}$ et al . Uso de desfibrilador automático externo en ambiente prehospitalario pervano: mejorando la respuesta a emergencias en Latinoamérica. Rev. bras. ter. intensiva. 2009;21(3).

8. Sardo PMG, Dal Sasso GTM. Aprendizagem baseada em problemas em ressuscitação cardiopulmonar: suporte básico de vida. Rev. Esc. Enferm. USP. 2008;42(4).

9. Ovalle CCIS et al. A Importância do Treinamento Prévio no Uso do Desfibrilador Externo Automático por Fisioterapeutas e Enfermeiros. Rev. bras. ter. intensiva. 2005; 17 (2).

10. Marco RM. Desfibrilador externo automático: un instrumento eficaz que puede aplicarse inefectivamente. Med. intensiva. 2003 [acesso 2013 jan. 09]; 27 (4): 229-31. Disponível em: http://www.elsevier.es/sites/default/files/ elsevier/pdf/64/64v27nO4a13046229pdfOO1. pdf

11. Guimarães HP, Lane JC, Flato UAP, Timerman A, Lopes RD. Uma breve história da ressuscitação cardiopulmonar. Rev. bras. clin. med. 2009; 7:177-87.

12. Miyadahira AMK et al. Ressuscitação cardiopulmonar com a utilização do desfibrilador externo semi-automático: avaliação do processo ensino-aprendizagem. Rev. Esc. Enferm. USP. 2008; 42(3).

13. Ornat JP. O papel do acesso a desfibrilação na cadeia de sobrevivência da parada cardíaca fora do hospital. Simpósio Virtual Mundial Sobre Morte Súbita. Richmond; [2O--].

14. Aehlert B. Emergências em cardiologia: suporte avançado de vida em cardiologia. $3^{a}$ ed. Texas: Elsevier, 2007.

15. Canetti MD et al. Manual básico de socorro de emergência para técnicos em emergências médicas e socorristas. $2^{\mathrm{a}}$ ed. São Paulo: Atheneu; 2007.

16. Caffrey SL et al. Public use of Automated External Desfibrillators. N Engl J Med. 2002; 347(16):1242-47.

17. AHA. Destaques das Diretrizes da American Heart Association 2010 para RCP e ACE. 2010.

18. Timerman $S$ et al. Rumo ao consenso internacional de ressuscitação cardiopulmonar e cuidados cardiovasculares de emergência $2 \mathrm{OlO}$ da Aliança Internacional dos Comitês de Ressuscitação. Rev. Soc. Bras. Clín. Méd. 2010; 8 (3).

19. Boaventura AP, Miyadahira AMK. Programa de capacitação em ressuscitação cardiorrespiratória com uso do desfibrilador externo automático em uma universidade. Rev. gaúcha enferm. 2012;33(1).

20. Bahia. Projeto de Lei $n^{\circ} 19.212$, de 30 de maio de 2011. Dispõe sobre a obrigatoriedade de disponibilização e manutenção de desfibrilador cardíaco externo automático, em locais públicos com grande concentração e circulação de pessoas no âmbito do Estado da Bahia.

21. Pernambuco. Assembléia Legistativa do Estado de Pernambuco. Outra morte em estádio por falta de desfibrilador preocupa. Diário Oficial do Estado, 25 out. 2006. Disponível em: http:// www.alepe.pe.gov.br/paginas/?id=3620\&dep $=41$ \&paginapai $=3596 \& d$ doc $=603 E 421 D A D C D 837 E O$ 3257211007C52C7

22. Brasil. Decreto-Lei n. 2.848, de 7 de dezembro de 1940. Código Penal. Disponível em: http://www2.camara.leg.br/legin/fed/ declei/1940-1949/decreto-lei-2848-7-dezembro1940-412868-norma-pe.html

23. Conselho Regional de Enfermagem de São Paulo. Parecer COREN-SP 26/2O13 - CT. Cardioversão, Desfibrilação e Uso do DEA. São Paulo; $2 \mathrm{Ol3}$. 